\title{
Literaturas lusófonas: apropriação e representação, regionalismo e religiosidade
}

Quem não vê bem uma palavra, não pode ver bem uma alma.

(Fernando Pessoa)

Márcia Silva Pituba Freitas ${ }^{1}$

Micheline Tacia de Brito Padovani ${ }^{2}$

\section{Considerações iniciais}

G ste capítulo tem por objetivos analisar o conto A menina de lá, de João Gui-

E marães Rosa, e o livro de literatura infantil O beijo da palavrinha, de Mia

1 Doutoranda em Língua Portuguesa pela Pontifícia Universidade Católica de São Paulo - PUC/SP. Membro do Grupo de Pesquisa de História das Ideias Linguísticas (Brasil e Portugal) e Identidade Nacional da PUC/ SP, coordenado pela Prof ${ }^{a}$ Dra Leonor Lopes Fávero. Contato: marpituba@hotmail.com.

2 Doutoranda em Língua Portuguesa pela Pontifícia Universidade Católica de São Paulo - PUC/SP. Membro do Grupo de Pesquisa de História das Ideias Linguísticas (Brasil e Portugal) e Identidade Nacional da PUC/SP, coordenado pela Prof ${ }^{a}$ Dra Leonor Lopes Fávero. Contato: michelinepadovani@yahoo.com.br. 
Couto, a fim de demonstrar como se dá o processo de apropriação e representação nessas duas narrativas literárias lusófonas. A análise será realizada com base nos princípios investigativos de Roger Chartier acerca da representação como polo de articulação de religiosidade, de regionalismo, de cultura e de mundo.

Parte-se de uma perspectiva sócio-histórica que busca, como fim, compreender as estratégias, o desenvolvimento e as transformações nas diversas apropriações e representações no contexto histórico e social em que as narrativas ocorrem. Assim, destacam-se alguns fatores que interferem na manipulação dos suportes culturais e que expõem as modificações das personagens, ao estabelecer as apropriações para a construção de sentido textual em linguagem literária.

A literatura, bem como as formas de ler o contexto social e histórico revelam a importância que as crenças, as intenções, as atitudes e as expectativas têm sobre o leitor durante o processo de apropriação e representação leitora. É válido dizer as imagens na literatura contemporânea lusófona tornaram-se um lugar para enfatizar as ações culturais e sociais, além de destacar a onipresença das personagens no enredo. Hernández (2007, p. 28) afirma que "É-nos dito que vivemos em um mundo em que tanto o conhecimento quanto muitas formas de entretenimento são visualmente construídos". Nossa leitura é marcada pelo repertório de conhecimentos diversos e pelo repertório visual que temos, ou seja, pela representação que fazemos durante a ação leitora.

\section{Representação, apropriação e literatura}

A literatura é abordada como perspectiva de determinado momento histórico e social, apresentando uma espécie de consciência social do contexto em que as narrativas se originam e mantem relações únicas e particulares. Neste sentido, as obras de Guimarães Rosa e de Mia Couto configuram-se como documento histórico, pois dão forma a questões provenientes e com forte ligação com a História.

A escrita literária caracteriza-se como projeto discursivo revelador de questões sociais e históricas de seu tempo, como: guerras, catástrofes, crenças, etc. Desse modo, a produção literária é uma base comunicacional, apresenta uma função social e acompanha, as transformações socioeconômicas por que vão passando as sociedades. É por meio da produção literária que as expressões, os significados e os relatos se formam possibilitando o aparecimento da literatura, da mesma forma que o discurso, pois "pode ser comparada a uma rede de lugares na sociedade, mas não pode encerrar-se verdadeiramente em nenhum território". (MAINGUENEAU, 2006, p.92). 
Literaturas lusófonas: apropriação e representação,

A propósito dessas afirmações, fazer parte do campo literário não significa "ausência de todo lugar, mas, como dissemos, uma negociação entre lugar e não-lugar, um pertencimento parasitário que se alimenta de sua inclusão impossível" (MAINGUENEAU, 2006, p.92). Ainda, conforme o autor:

Suporte de um ato de discurso socialmente reconhecido, a obra é enunciada através de uma instituição, no caso, um gênero de discurso determinado que ele próprio, num nível superior, mobiliza essa vasta instituição que é a literatura. As condições de enunciação vinculadas a cada gênero correspondem a outras tantas expectativas do público e antecipações possíveis dessas expectativas pelo autor (MANGUENEAU, 1995, p.122).

A literatura mobiliza tanto o enunciador quanto o leitor - o coenunciador por meio da reconstrução das pistas textuais e da significação da obra durante o processo de recepção textual. O leitor é capaz de estabelecer e antecipar relações entre língua, linguagem, história, sociedade e vida. Nesse momento e nesse lugar, ocorre um jogo dialético, em que ele busca compreender-se e situar-se no mundo e, procura entender tanto a relação que trava consigo quanto com os outros e com o mundo. Dessa forma, revela-se a interioridade de sua essência. A literatura possibilita a compreensão da humanidade pelo sujeito-leitor - tanto dentro quanto fora de si - e da ocorrência dos fatos históricos em um dado momento. Assim, uma análise da linguagem não pode ignorar a literatura, pois ela faz parte da construção da língua.

A história cultural do mundo social proposta por Roger Chartier busca fazer reconsiderações dos acontecimentos e fenômenos históricos a partir das noções de representações e práticas sociais fundamentais para complementar e articular a cultura e o mundo. Em A História Cultural: Entre práticas e representações, Chartier (1990) discorre sobre o conceito de cultura retomando Geertz:

O conceito de cultura ao qual adiro [...] denota um padrão, transmitido historicamente, de significados corporizados em símbolos, um sistema de concepções herdadas, expressas em formas simbólicas, por meio das quais os homens comunicam, perpetuam e desenvolvem o seu conhecimento e as atitudes perante a vida. (CHARTIER 1990, p. 66-67).

Diante do exposto por Chartier (1990), podemos dizer que a cultura está condicionada por uma representação ideológica em situação comunicativa na interação social que revela também questões de poder e de luta, econômica e 
histórica. Assim, o autor conceitua cultura como prática social e propõe que seu estudo aborde duas categorias: representação e apropriação.

Dessa forma, ao abordarmos as questões relativas à religiosidade e ao regionalismo, atemo-nos à noção mencionada por Chartier (1988) em que a representação é posta como instrumento teórico-metodológico de análise da história cultural. Assim, o autor afirma:

As representações do mundo social assim construídas, embora aspirem à universalidade de um diagnóstico fundado na razão, são sempre determinadas pelos interesses de grupo que as forjam. Daí, para cada caso, o necessário relacionamento dos discursos proferidos com a posição de quem os utiliza. (...) As percepções do social não são de forma alguma discursos neutros: produzem estratégias e práticas (sociais, escolares, políticas) que tendem a impor uma autoridade à custa de outros, por elas menosprezados, a legitimar um projeto reformador ou a justificar, para os próprios indivíduos, as suas escolhas e condutas. Por isso esta investigação sobre as representações supõe-nas como estando sempre colocadas num campo de concorrências e de competições cujos desafios se enunciam em termos de poder e dominação. As lutas de representações têm tanta importância como as lutas econômicas para compreender os mecanismos pelos quais um grupo impõe, ou tenta impor, a sua concepção do mundo social, os valores que são seus, e o seu domínio. Ocupar-se dos conflitos de classificações ou de delimitações não é, portanto, afastar-se do social - como julgou uma história de vistas demasiado curtas -, muito pelo contrário, consiste em localizar os pontos de afrontamento tanto mais decisivos quanto menos imediatamente materiais (CHARTIER, 1988, 17).

O autor ainda destaca que "as representações são sempre determinadas pelo interesse dos grupos que as forjam" (CHARTIER, 1988, p. 17). Diante disso, a concepção de representação atua como instrumento teórico-metodológico que apreende em campo histórico particular a internalização simbólica entre os indivíduos e seus representantes e apreende as lutas pelo poder e pela dominação entre grupos, estruturadas com base em relações externas objetivas produzidas em determinado campo social. Assim, por meio da representação é possível "ver uma coisa ausente" instituída a partir da "exibição de uma presença”. O autor considera esse conceito superior ao de mentalidade.

A apropriação visa a uma história social das interpretações por meio das determinações sociais, institucionais e culturais produzidas nas práticas sociais "[...] práticas que, pluralmente, contraditoriamente dão significado ao mundo" 
Literaturas lusófonas: apropriação e representação, regionalismo e religiosidade

(CHARTIER,1988, p. 27). A articulação entre o mundo do texto literário e o mundo do sujeito é capaz de refletir com a apropriação do discurso as maneiras como os aspectos históricos e culturais afetam o leitor e conduzem para a compreensão do contexto histórico, de identidade e de religiosidade encontradas nas narrativas. Conforme apontam Charaudeau e Maingueneau (2004, p. 127), o contexto pode ser linguístico e não linguístico. Assim os autores se manifestam:

[...] o contexto não linguístico, o contexto estrito (ou micro) faz sobressair, por exemplo, o quadro espaciotemporal e a situação social local nos quais a troca comunicativa, seus participantes (número, características, status, papéis, e a relação que mantêm entre si), o tipo de atividade e as regras que a regem [...]. Enfocado de forma abrangente, o contexto (nível macro) faz sobressair o aspecto institucional último será o conjunto do mundo físico, e o quadro institucional último será o conjunto do mundo social.

Logo, é válido dizer que o contexto se caracteriza pela situação históricosocial em que o texto é produzido, pois leva-se em consideração a produção humana, ou seja, as produções realizadas durante ato discursivo de comunicação. Com isso, o contexto social considera elementos e manifestações da realidade dos envolvidos na interação discursiva.

\section{Representação e apropriação em Mia Couto e Guimarães Rosa}

\section{O beijo da palavrinha}

O texto de Mia Couto, O beijo da palavrinha, traz a história de Maria Poeirinha. Passa-se em um ambiente familiar, cujos parentes mais próximos, destacados na narrativa, são: seu irmão, Zeca Zonzo, e seu tio, Zé Litorâneo. A relação entre representação e apropriação ocorre por meio tanto da linguagem verbal quanto da linguagem não verbal.

De forma lúdica e que explora a estética, o texto apresenta imagens que remetem à pintura - mostradas por meio de telas -, que contam uma história e acabam por reproduzir uma realidade sociocultural moçambicana. Dessa forma, as imagens atuam de modo a destacar apontamentos ideológicos e culturais do contexto moçambicano.

O leitor pode ter diferentes formas de experiências representativas durante a leitura, pois a obra permite que sejam feitas leituras de formas isoladas tanto 
das imagens/pinturas quanto do texto escrito. Também é possível fazer, leitura ambivalente a partir de ambas as linguagens, em que a linguagem verbal e a não verbal se potencializam mutuamente. Além disso, ocorre outra forma de leitura, na qual em que sejam confrontas as linguagens, em oposição, sem que haja prejuízo de compreensão. Portanto, o leitor tem a liberdade de dar o tom da sua leitura pela possibilidade de construção de novas maneiras de ver, absorver e posicionar-se no mundo das palavras a partir de cada nova experiência (BASTAZIN, 2018).

Dessa maneira, as linguagens artísticas - literatura e pintura - articulam-se no texto literário e complementam-se para a construção de sentido. As imagens da ilustradora moçambicana Malangatana Ngwenya são autônomas e repercutem a temática do livro, dialogando intensamente com a palavra poética do também moçambicano Mia Couto. Barbieri e Vilela (2018, p. 94) afirmam que "na junção entre as águas dos rios (as palavras) e as águas dos mares (as imagens) é que os encontros se dão, é que as relações acontecem. A foz, o encontro do rio com o mar, é o livro ilustrado, onde a imagem e a palavra se encontram e se misturam".

Ao final da narrativa, os quadros constituem uma totalidade, um conjunto de telas que explicitam a africanidade na cultura moçambicana, mostrada para o mundo, representando a identidade de um povo, seja por meio das peculiaridades linguageiras, seja por meio das peculiaridades regionalistas. Por isso, Bastazin (2018, p. 76) afirma que

\begin{abstract}
Palavra e imagem - enquanto objeto sonoro, visual e tátil - entram em interação sem exigir necessariamente vínculos de significado. Se, de um lado, elas podem relacionar-se para ampliar um possível significado, de outro, elas podem também dizer suas diferenças, suscitando relações de complementariedade ou mesmo oposição. A obra infantil se oferece como experiência de ampliação de perspectivas, como universo sem fronteiras, como imaginário aberto às possibilidades de uma mente plástica em permanente transformação.
\end{abstract}

No cruzamento das linguagens artísticas, a imagem constitui-se um elemento supremo de composição da linguagem literária, ela tem o poder de expressar e de condensar a imaginação humana. O leitor apropria-se das imagens ao longo da leitura e, no decorrer da leitura, elas transmitem mundos possíveis dentro de sua própria origem.

Calvino (2010) também afirma que as imagens são carregadas de significado, permitindo ao leitor apropriar-se do mundo da personagem, além de vivenciar o que ela está sentindo. Com isso, a apropriação da imagem possibilita a expansão da compreensão a ponto de explodir, produzindo outras imagens que, antes, 
Literaturas lusófonas: apropriação e representação,

estavam ocultas, "forma-se um campo de analogias, simetrias e contraposições" (CALVINO, 2010, p.104).

As imagens provocam, por meio da representação, conhecimento ou reconhecimento de elementos culturais e ideológicos da sociedade moçambicana, ou seja, várias vozes discursivas estão representadas em tais imagens: o colonizador, o colonizado, a pobreza social e outras, embora sejam abordadas com leveza poética. Ao tratar da morte de Poeirinha, por exemplo remete-se à ruptura e à liberdade. Dessa maneira, a linguagem literária e as imagens facilitam a representação e a apropriação do mundo a partir de uma percepção visual, dando margem a uma percepção dialética.

Maria Poeirinha era uma menina que não conhecia o mar, mas que sonhava em conhecê-lo; sonhava em converter-se em água e ser a princesa de um livro em que arrastava um manto feito de redemoinhos, remendos e retalhos. As vozes polifônicas apontam diversas questões do contexto moçambicano.

O mar representa não só o passado de Moçambique, pois foi por ele que os colonizadores chegaram, mas também a renovação, já que as águas lavam fragmentos de uma realidade sangrenta, que ocorreu durante os conflitos internos. Além disso, o mar representa a cura para Maria Poeirinha. Ele é o caminho para o infinito, é representação de determinadas ações, como a exploração do mundo sem obrigatoriedade, apenas pela necessidade de adaptar-se e equilibrar-se.

A representação permite um encontro estético-literário realizado por meio da linguagem verbal, em discurso literário, e que, aos poucos, conduz o leitor a um mundo imagético, em que Zeca Zonzo faz o seu contorno. Ele é o irmão da menina e tem o rótulo de ser desprovido de juízo. No entanto, talvez por essa razão, ele é quem tem a clarividência de apresentar o mar a Poeirinha, além do olhar comum da mediocridade.

Podemos afirmar que ele salva Maria Poeirinha, pois ela tem o prazer de conhecer o mar da forma mais inusitada, particular e íntima possível: adentrado nas suas peculiaridades e nos seus meandros. Assim, Zeca Zonzo possibilita que, junto com ela, o leitor construa outro olhar e desenvolva outra compreensão de mundo. Ele estabelece a representação e a apropriação com os demais elementos da vida, de forma espontânea. Por isso, é uma atividade espontânea. Bastazin (2018, p. 77) afirma que

A linearidade temporal e a definição objetiva dos espaços físicos abandonaram há muito as páginas infantis. Os olhos, antes de decodificarem palavras, passeiam pela espacialidade que sustenta a ilustração. Linhas, cores e texturas criam movimento e não importa, necessariamente, o que vem antes ou depois: o traço ou a cor, a palavra ou o desenho; 
mesmo porque, muitas vezes, a própria palavra assume uma forma que lhe atribui novas significações.

Nesse momento, o leitor é transportado para dentro do enredo a fim de acompanhar as ações que se desencadearão antes da morte de Poeirinha. $\mathrm{O}$ menino pega papel e caneta, e, com "letra gorda”, escreve a palavra MAR. Logo em seguida, passa o dedo da irmã sobre a letra $M$, que é feita de "vagas, líquidas linhas que sobem e descem", conversando e procurando fazê-la sentir o mar por meio da palavra MAR. Ali, a letra M representa as ondas do mar, em um momento de cumplicidade, sensibilidade, solidariedade e muita imaginação entre os dois . Com muita sensibilidade e sutileza, Couto (2008, p. 14-16) cria uma narrativa poética em que uma palavra tão pequena assume, por meio das letras que a compõem, um sentido grandioso e assim narra:

- Vou-lhe mostrar o mar, maninha. Todos pensaram que ele iria desenhar o oceano. Que iria azular o papel e no meio da cor iria pintar uns peixes. E o Sol em cima, como vela de bolo de aniversário. Mas não. Zonzo apenas rabiscou com letra gorda a palavra 'mar'. Apenas isso: a palavra inteira e por extenso Diante do espanto de todos, a menina conseguiu vislumbrar o mar, e, conforme as palavras do mano Zonzo, "se afogou numa palavrinha".

Com a apropriação da palavra "mar", a criança explora seus sentimentos, emoções, bem como o mundo exterior por meio das percepções representadas pela palavra em questão. As situações do mundo real nem sempre oportunizam a exploração dos sentimentos ou o exame das reações emocionais da mesma forma que a fantasia de uma situação lúdica, que se abre com a apropriação e afasta procedimentos desgastados pela razão.

A narrativa aponta que "a palavra escrita tem lugar marcado na representação de um universo que integra uma cultura de tradição oral e formas diversas de escrita" (MACEDO \& MAQUÊA, 2007, p.68-68). A leveza da infância é retomada pelas descobertas de um mundo novo e, ao mesmo tempo, pela dor e pelo sofrimento. $\mathrm{O}$ enredo mostra-nos a aproximação com a linguagem cinematográfica: close, imagens panorâmicas, ponto de vista de cima para baixo ou ao seu reverso, técnica de cortes inerentes à montagem cinematográfica, acelerando o tempo narrativo, voltando ao passado ou resumindo um evento em verdadeiras metáforas. Esses elementos da linguagem cinematográfica enfatizam a leveza do imaginário na infância.

Essa aproximação com a linguagem cinematográfica possibilita que haja um encaminhamento para o desfecho da narrativa. A “desrazão” de Zeca Zonzo 
Literaturas lusófonas: apropriação e representação,

consegue guiar os dedos da irmã para a leitura de um mundo por ela desconhecido, que vai sendo construído aos poucos pela relação tátil com o papel, no qual a palavra está escrita, "Zeca Zonzo levantou os dedos da irmã e soprou neles como se corrigisse algum defeito e os ensinasse a decifrar a lisa brancura do papel" (COUTO, 2008, p. 18).

O que se vê é uma sequência da narrativa em que há a construção de um momento mágico e de apropriação de um mundo a fazer sentido. Assim, a palavra MAR, por meio das letras: $M, A, R$, ganha força imagética de uma realidade ideogramática das ondas, da gaivota e da rocha que se distinguem e são apreciadas pelos dedos da menina. A letra A é uma gaivota pousada nela própria e, por fim, resta que os dedos da menina se magoem "no ' $\mathrm{R}$ ' duro, rugoso, com suas ásperas arestas".

A imagem torna-se realidade para a menina, que se salva ao fazer a representação do mar por meio das ondas, da gaivota e da rocha. Do mesmo modo, a linguagem imagética - fotográfica e cinematográfica - concretiza a escrita de Zeca Zonzo aproximando o mundo representado. A imagem fotográfica em diálogo com o texto literário destaca a visibilidade do novo mundo. Essa compreensão da imagem-quadro ajuda no entendimento; texto e imagem caminham juntos para a construção de sentido, com as percepções imagéticas e literárias unidas.

$\mathrm{O}$ conto de Mia Couto apresenta a possibilidade que a personagem tem de conhecer e sentir o mar mesmo estando longe dele. Assim, as imagens em conjunto com o texto incentivam o acesso ao conhecimento, a elaboração de sentimentos e o desenvolvimento humano por meio da literatura e da relação interartes.

Dessa maneira, a personagem Maria Poeirinha consegue, por meio da representação e da apropriação da palavra MAR, sentir e desapegar-se da vida. De forma lúdica, a personagem morre. Com isso, a literatura possibilita que o leitor, ao se confrontar com a narrativa, se posicione diante do que foi exposto, manifestando-se perante a interpretação do mundo olhada pelo escritor, mas que é percebida, imaginada e sentida pelo outro.

\section{A menina de lá}

O encantamento a que Guimarães Rosa nos expõe desde o título do conto já está centrado no poder das palavras. Ele as explora à exaustão, por meio das escolhas lexicais manifestadas em componentes alegóricos, carregados de simbologia e que brotam de uma semântica particular, de um mundo individualizado, mas, ao mesmo tempo, de uma polissemia latente, mirada e atingida. Assim, o texto nos permite concomitantemente apontar um problema social e a poesia que revela uma faceta da infância do sertão nordestino. 
Dentro de uma literatura que mais insiste em imitar a criar, com uma elaborada linguagem regionalista, Guimarães Rosa traz à tona a similaridade pela diferença. Nesse sentido, ele pensa o igual como diferente e, embora pareça paradoxal, distingue produzir semelhança de reproduzir. Há uma performance de pensamento visível com base na expressividade da construção de seu texto.

Quando nos envolvemos com a leitura, criamos um jeito novo de sentir o texto. A presença do corpo é inevitável, pois ele interage com o texto e está ansioso por novas experiências e descobertas. As emoções afloram quanto mais avançamos e adentramos nos labirintos da narrativa. Sentimos sinestesicamente o conto porque ele é real, descreve pessoas reais. Dessa forma, Rosa, com toda a sua genialidade, desmonta a realidade indiferente, arrogante e esnobe e a reconstitui com alteridade, empatia e compaixão.

A representação e a apropriação se dão por meio da linguagem verbal. Já no começo do conto, é possível destacar a representação na leitura do título - a menina de lá,que nos coloca em um lugar de contraposição -, cá, aqui. No decorrer do conto, vamos nos aproximando dessa menina e criamos uma relação com ela. Dessa forma, percebem-se as apropriações próprias do texto de Rosa. O pai e a mãe da menina não têm nome próprio, mas são identificados por Pai e Mãe, com iniciais maiúsculas, o que confere um ar de pessoalidade. A menina dá características aos seus pais: Mãe - menina grande e o Pai - menino pidão.

A menina, ao contrário, recebe no nascimento o nome de Maria, embora seja mais conhecida por Nhinhinha - um nome com diminutivo, o que remete à condição física da menina marcada por fragilidade e delicadeza. Não por acaso, nhê, nhê, nhê é fala, fala, fala em tupi-guarani. Além dessa menção à cultura indígena, existem outras, tais como o prato de folha, a marcação de tempo por meio dos elementos da natureza, bem como o passar vagaroso do tempo, sem o atropelamento das horas motivado pela correria dos grandes centros urbanos onde se sugere que o tempo anda mais rápido e acelerado.

A comunicação com Nhinhinha é custosa; na contramão da fala, há uma relação de diálogo desafiadora. Os pais agem como crianças em início de vida, e a protagonista é colocada como a detentora de um saber construído em tão poucos anos de vida: surpreende com seus neologismos e enche de autoridade a sua existência, apropriação natural da própria condição de vida dos nordestinos. "O sertanejo, é antes de tudo, um forte".

Nhinhinha mais observa que fala, atitude comum aos sábios e aos pensadores. De repente, em meio àquela condição de vida tão previsível, determinista e sem novidades, começa a adivinhar acontecimentos próximos, e isso se torna

3 Famosa frase do livro Os Sertões de Euclides da Cunha 
Literaturas lusófonas: apropriação e representação,

o que não se entende, o que não se consegue explicar senão pela presença do fantástico, do sagrado e, porque não acrescentar, do religioso, do místico. Em um primeiro momento, podemos nos indagar: Nhinhinha é uma santa ou uma bruxa? Fica um suspense: "Está trabalhando um feitiço..." (ROSA, 2001, p.69).

Entretanto, a partir das pistas dos seus gestos e das poucas palavras que solta, percebemos um deslocamento da menina para um não lugar. Dessa forma, ela descola-se de um pertencimento familiar natural: nem está no mundo infantil, e nem se encaixa no mundo adulto. É um ser símbolo/representação de sacralidade e de religiosidade e, não há explicação para o que ela faz acontecer, até que recebe o status de santa, alto grau que se alcança no sertão por quem adivinha chuva e cura doentes: "A Mãe, que a olhava com estarrecida fé, sarou-se então, num minuto" (ROSA, 2001, p.70). E tão importante quanto tudo dito, é que a menina sabe que a sua passagem pela Terra é efêmera. Os puros de coração vivem pouco.

A leitura do conto abre vezes às sensações, pois há uma estética que joga com o dito e o não dito. Podemos criar afeto, memória e saberes a partir de Nhinhinha. Olhamos para ela e deixamos que ela também nos olhe. Dados do real se entrelaçam com a fantasia e o imaginário, e essa percepção é um estado de arte que ocorre por meio da experiência. As lacunas deixadas por Rosa permitem que o leitor, formando-se como sujeito, faça a sua parte no processo de construção da leitura e complete esses espaços de acordo com a sua forma particular de perceber o mundo. Por isso, Bastazin (2018, p. 72) afirma que

[...] é tempo de enfrentarmos com determinação que a arte não pode e não deve correr o risco de ser relegada a uma importância menor, complementar e opcional no processo de formação humana. A prática do literário - como produção de leitura - é um caminho essencial para a formação do indivíduo; é um território de exploração necessária para abrir espaços à produção do prazer e do conhecimento.

Contamos histórias para justificar a nossa presença na Terra, para explicar o indizível e o que simplesmente se sente, elas são um sobrevoo na sociedade. Precisamos entrar no mundo do outro para aprender a entendê-los: o mundo e o outro. Só tomamos posse desse conhecimento pela compreensão. Quando entramos em contato com a história do outro, deixamos de sentir a nós mesmos e passamos a sentir as dores do outro - empatia e alteridade.

Nesse sentido, Bastazin (2018, p. 75, grifos da autora) afirma que "o ato de leitura ou, ainda, de manusear o livro representa um momento de encontro com o outro e de satisfação, seja pela curiosidade, seja pelas descobertas que envolvem esse momento mágico". Essa experiência de literatura é possível por meio da arte na/pela linguagem. Sobre isso, a autora ainda afirma: 
[...] falar em língua é lidar com identidade e compartilhamento sociocultural, a partir de um sistema predeterminado e convencional; falar em linguagem é expandir território, é pensar e viver da universalidade das potências expressivas do ser; é ultrapassar fronteiras, considerar semelhanças e respeitar e usufruir diferenças. Discutir o literário é enfrentar e viver no território da diversidade e aprender a expandir-se no contexto desses valores: movimentar-se na leitura do literário é fecundar a capacidade de (re)descobrir-se no percurso da vida, de aprender com a linguagem a mobilidade do olhar e a plasticidade de que é feita a nossa mente (BASTAZIN, 2018, p. 72).

A arte pode colocar o leitor em crise. Quem lê e abandona-se na leitura está suscetível a passar por um momento conflituoso, uma vez que emerge um cenário crítico em que são produzidas imagens mentais a partir do desencadeamento de ações descritas. Isso dá um ar de verossimilhança aos atos e fatos narrados e contribui para que o leitor dê vida ao conto. Nesse momento, esse interlocutor é o diretor do filme montado com base na sua criação imagética mental permeada das fantasias que rondam o seu pensamento. Quando ocorre esse processo, é inevitável ao leitor não criar intimidade ou, pelo menos, se envolver com a trama.

Em decorrência de todo esse processo, esbarramos em uma situação difícil, em que incertezas são geradas, e é necessário que o sujeito responda com reflexão, posicionamentos e mudanças com base no experimentado. Crise vem do grego e significa ruptura, o que pode ensejar uma ideia de romper com o passado, de dar uma pausa para, em seguida, trilharem-se novos caminhos, com novas perspectivas. Isso requer que aconteçam profundas mudanças e alterações do status quo. Após ler um texto em que o sujeito se ponha em crise - porque, sim, a arte proporciona esse estado - o leitor sai transformado em seu estado de espírito, metamorfoseado em suas ideias, e é provável que problematizações e questões sejam suscitadas em seu diálogo particular, de forma que fiquem em xeque as certezas de suas (in)verdades.

\section{Considerações finais}

O espaço literário está aberto à diversidade. Não há fronteiras e, nele, cria-se um campo tanto para o inventivo quanto para o universal. Por isso, ao confrontarmos as duas histórias, podemos observar que tratamos de duas Marias: a Maria Poeirinha e a Maria mais conhecida como Nhinhinha. Maria é um nome comum e, como representação religiosa, simboliza a Virgem Maria, a Mãe de Jesus Cristo. Maria é uma mulher pura, casta, sem pecado original e que 
Literaturas lusófonas: apropriação e representação, regionalismo e religiosidade

viveu para fazer o bem. Isso se encaixa perfeitamente ao caráter das primeiras Marias - representação e apropriação.

A relação entre literatura e imagem ocorre de forma muito estreita, a ponto poder dizer que "as ilustrações abandonaram o modesto papel de ficar a serviço do que relatam as palavras e passaram a constituir um outro texto, de natureza visual, que estabelece interação com o verbal. Assim, ambos se tornaram igualmente fundamentais no livro para crianças" (CADEMARTORI, 2009, p. 51). As imagens convidam, desafiam e conduzem o leitor a leituras inusitadas por meio da linguagem imagética, visando à reprodução de estratégias visuais do contexto sócio-histórico no qual está inserida a narrativa. Desse modo, o leitor é levado a uma representação de mundo.

Na música Pais e filhos, de Renato Russo, gravada pela banda Legião Urbana, há um trecho que diz assim: "Meu filho vai ter nome de santo, quero o nome mais bonito". É muito comum, nos países colonizados por Portugal, em que a primeira cultura difundida maciçamente foi a lusa, que as tradições do colonizador prevaleçam. Com isso, a fé que domina é a católico-cristã. Por essa razão, o nome de batismo deve estar ligado a um nome de santo para dar boa sorte, proteção e bênção.

Em ambas as histórias, aqueles que são aparentemente vulneráveis acabam sendo os mais fortes ou mais inteligentes. Nhinhinha mostra-se assim do começo ao fim do conto. Outro exemplo é Zeca Zonzo, em O beijo da palavrinha, que chega a ser descrito como desprovido de juízo, cabeça no ar e com ideias que voavam como balões em fim de festa. No entanto, ele é quem consegue apresentar a Poeirinha o mar. É por meio da sinestesia que as letras despertam; pela decomposição da palavra, Poeirinha consegue ter uma experiência com o mar não por meio de imagens, mas pelo jogo de signos, significados e significantes usados por Zeca.

Nhinhinha, assim como Poeirinha, é uma menina de lá, de outro lugar, que não desse mundo. Por isso, ambas acabam indo embora mais cedo. Elas vêm para ensinar mais que aprender. Nesse ponto, saltam aos olhos a mística e a religiosidade, elementos presentes nas narrativas que se cruzam com o regionalismo característicos dos autores das histórias. Essas meninas são uma linha tênue entre a sabedoria, a tolerância e a compaixão e a pureza, a delicadeza e a fragilidade.

Por fim, as duas narrativas acontecem no aconchego familiar, lugar de pertencimento, onde, até nós, leitores, acabamos nos sentindo também da família. Estamos lá juntos com todos os demais, pois o lar é o grande ninho de acolhimento em que se passam as histórias. Nesse local, elas se desenvolvem, ganham corpo e significado. E, dessa forma, demonstramos como estão presentes nas histórias mencionadas a representação e a apropriação. 


\section{Referências}

BARBIERI, Stela; VILELA, Fernando. Desencontros da palavra com a imagem. In: NAVAS, Diana; CARDOSO, Elizabeth; BASTAZIN, Vera (orgs.). Literatura e ensino: territórios em diálogo. São Paulo: EDUC: Capes, 2018. p. 91-102.

BASTAZIN, Vera. Da mobilidade do olhar à plasticidade das ideias: uma trilha pela literatura infantil. In: NAVAS, Diana; CARDOSO, Elizabeth; BASTAZIN, Vera (orgs.). Literatura e ensino: territórios em diálogo. São Paulo: EDUC: Capes, 2018. p. 69-80.

CADEMARTORI, Ligia. Para não aborrecer Alice: a ilustração no livro infantil. In: PAIVA, Aparecida; SOARES, Magda (Orgs.). Literatura infantil: políticas e concepções. Belo Horizonte: Autêntica, 2008, p. 79-90.

CALVINO, Italo. Seis propostas para o próximo milênio. 3 ed. São Paulo: Companhia das Letras, 2010.

CHARAUDEAU, Patrick. Para uma Nova Análise do Discurso. In: CARNEIRO, A.D. (Org.) O Discurso da Mídia. Rio de Janeiro: Oficina do autor, 1996.

CHARAUDEAU, Patrick.; MAINGUENEAU, Dominique. Dicionário de análise do discurso. Coordenação da tradução Fabiana Komesu. São Paulo: Contexto, 2004.

CHARTIER, Roger. A história cultural: entre práticas e representações. Trad. Maria Manuela Galhardo. Lisboa: Difusão Editorial, 1988.

CHARTIER, Roger. Formas e sentido. Cultura escrita: entre distinção e apropriação. Trad. Maria de Lourdes Mierelles Matêncio. Campinas/SP: Mercado de Letras, 2003.

COUTO, Mia. O Beijo da Palavrinha. Ilustração de Malangatana. Rio de Janeiro: Língua Geral Editores, 2006.

GENETTE, Gérard. Paratextos editoriais. Cotia, SP: Ateliê Editorial, 2009.

HERNÁNDEZ, Fernando. Catadores da cultura visual: proposta para uma nova narrativa educacional. Porto Alegre: Mediação, 2007.

MAINGUENEAU, Dominique. O contexto da obra literária. 1, ed. São Paulo: Martins Fontes, 1995.

MAINGUENEAU, Dominique. Termos chave da análise do discurso. Uberlândia: Editora UFMG. 2006.

MAINGUENEAU, Dominique. Gênese dos discursos. Tradução Sírio Possenti. São Paulo: Parábola, 2008.

ROSA, João Guimarães. Primeiras Estórias. Rio de Janeiro: Nova Fronteira, 2001. 